\title{
Costs of fragility hip fractures globally: a systematic review and meta-regression analysis
}

Sam Williamson ${ }^{1}$, Filipa Landeiro ${ }^{1}$, Thomas McConnell ${ }^{1}$, Lucy Fulford-Smith ${ }^{1}$, M Kassim Javaid², Andrew Judge ${ }^{2}$, José Leal ${ }^{1}$

${ }^{1}$ Health Economics Research Centre, Nuffield Department of Population Health, University of Oxford, Oxford, UK

${ }^{2}$ Oxford NIHR Musculoskeletal Biomedical Research Unit, Nuffield Department of Orthopaedics, Rheumatology and Musculoskeletal Sciences, University of Oxford, Oxford, UK

Email address and telephone number of corresponding author

José Leal, DPhil. Jose.leal@dph.ox.ac.uk

\section{Mini-abstract}

Understanding the cost of hip fractures is important in informing policy decisions on preventative treatments. We reviewed the literature for studies reporting costs of hip fractures and identified 113 studies. We estimate the initial hospitalisation to cost $\$ 10,075$ with significant variation by region, gender and year of study.

\begin{abstract}
Purpose - To systematically review the costs of hip fractures globally and identify drivers of differences in costs.

Methods - A systematic review was conducted to identify studies reporting patient level fragility hip fracture costs between 1990 and 2015. We extracted data on the participants and costs from these studies. Cost data concerning the index hospitalisation were pooled and a meta-regression was used to examine its potential drivers. We also pooled data on the first year costs following hip fracture and considered healthcare, social care as well as other cost categories if reported by studies.

Results - 113 studies reported costs of hip fracture based on patient level data. Patients developing complications as well as patients enrolled in intervention arms of comparative studies were found to have significantly higher costs compared to the controls. The pooled estimate of the cost for the index hospitalisation was $\$ 10,075$. Health and social care costs at 12 months were $\$ 43,669$ with inpatient costs being their major driver. Meta-regression analysis identified age, gender and geographic region as being significantly associated with the differences in costs for the index hospitalisation.
\end{abstract}

Conclusions - Hip fracture poses a significant economic burden and variation exists in their costs across different regions. We found that there was a considerable variation across studies in terms of study design, methodology, follow up period, costs considered and results reported that highlights the need for more standardisation in this area of research.

\section{Keywords}

Systematic review, Meta-regression, Hip fracture, Costs

\section{Conflicts of Interest -}

S.W., F.L., T.M., L.F-S. and J.L. report no conflict of interest. 
M.K.J. has received in the last 5 years honoraria for travel expenses, speaker fees and/or advisory committees from Lilly UK, Amgen, Servier, Merck, Medtronic, Internis, Consilient Health and Jarrow Formulas. He also serves on the Scientific Committee of the National Osteoporosis Society and International Osteoporosis Foundation.

A.J. has received consultancy, lecture fees and honoraria from Servier, UK Renal Registry, Oxford Craniofacial Unit, IDIAP Jordi Gol, and Freshfields Bruckhaus Deringer, has held advisory board positions (which involved receipt of fees) from Anthera Pharmaceuticals, Inc., and received consortium research grants from ROCHE.

\section{Acknowledgements}

This project was funded by the NIHR Health Services and Delivery Research programme (project number 11/1023/01).Support was received from the Oxford NIHR Musculoskeletal Biomedical Research Unit, Nuffield Orthopaedic Centre, University of Oxford. S.W. received support from NIHR as Academic Clinical Fellow in Public Health.

The views and opinions expressed therein are those of the authors and do not necessarily reflect those of the HS\&DR programme, NIHR, NHS, or the Department of Health. 


\section{Introduction}

Hip fractures are an important cause of death and disability worldwide, particularly amongst older people. They are associated with physical and mental disability as well as high mortality and hospital costs [1-3]. In 1990 it was estimated that, globally, there were 1.6 million hip fractures [4]. Due to an ageing population, the number of hip fractures is expected to rise steeply, especially in Asia [5,4]. By 2050, the annual incidence of hip fracture worldwide will rise to over 6 million [6].

A history of falls and underlying osteoporosis are the leading risk factors for sustaining a fragility hip fracture in older age $[7,8]$. Bone mineral density decreases with age and at a faster rate in women [9]. Consequently, the prevalence of osteoporosis and hip fractures are highest in older women [10]. In 2000 , it was estimated that $23 \%$ of post-menopausal white women in the United States of America (US) were living with osteoporosis and a further $54 \%$ had osteopenia, a milder form of the disease [4]. Together, osteoporosis and osteopenia account for over five million Disability Adjusted Life Years (DALYs) annually [11]. Fragility hip fractures contribute more than $40 \%$ of the DALYs caused by osteoporosis [2]. The mortality rates of these individuals vary between $8.1-10.5 \%$ at 30 days and $21.6-31.2 \%$ at one year $[12,3,13]$.

Evidence accumulates on interventions to reduce the burden of disease from hip fractures by preventing falls; optimising hospital recovery; implementing secondary fracture prevention services, e.g. fracture liaison services; and diagnosing and treating osteoporosis with bone resorptive drugs. Policy decisions regarding investing in new services or interventions require up-to-date knowledge of the economic burden of hip fracture and cost-effectiveness analyses of the interventions being considered. Accurate data on the cost of hip fractures is an essential consideration when estimating the impact of hip fractures and osteoporosis as well as being a major input in cost-effectiveness analyses.

The aim of this study is to systematically review the costs of fragility hip fractures globally and, where possible, identify the key drivers of the differences in costs.

\section{Methods}

\section{Literature search}

The selection of electronic databases and the search strategy were developed with an information specialist at the University of Oxford and in line with preferred reporting items for systematic reviews and meta-analyses (PRISMA) [14]. MEDLINE, Embase, EconLit, Global Health, CAB abstracts, NHS EED \& HTA and Web of science databases were searched (see Appendix 1 for search strategies).

Study selection

The outcome of interest was the cost of hip fracture. Studies reporting costs based on patient level datasets were included. Studies published before 1990, or if the year of costing was before 1990 were excluded. Studies not in English and not published in peer-reviewed journals were also excluded. Where multiple studies used the same patient cohort, data extraction was restricted to the paper reporting the most detailed information.

References were searched to identify studies missed by the electronic search. The grey literature was not reviewed.

Data extraction and management 
Data were extracted from included studies using a standardised data sheet by two reviewers (see Appendix 2). Comparison of data extracted by reviewers was performed for 88 studies (78\%). Discrepancies between reviewers were resolved through discussion among authors.

Data extracted included details on study design, sample population, economic perspective and results of the study. Follow up was assumed to be the mean length of stay for studies reporting only costs for the initial hospital inpatient admission. Additional factors related to the country in which participants lived were obtained from World Bank datasets. Data were extracted on Gross Domestic Product (GDP), national healthcare expenditure per capita and the proportion of total healthcare expenditure that was public [15-17].

Risk of bias was assessed using a 14 point quality checklist based on what was used in National Institute for Health and Care Excellence (NICE) guidelines for evaluating costing studies economic evaluations (Appendix 3) [18]. Quality scores from researchers were cross checked for 86 studies (76\%).

Results of subgroup or regression analysis were extracted with details of the variables assessed. Results were coded as being associated with either significantly higher or lower costs $(p<0.05)$ or with no difference in costs.

All reported costs were extracted as mean costs per patient. If studies reported the total cost incurred by a cohort, the mean cost per patient was imputed. Costs were assigned to the category(ies) of care the cost related to (see Figure A5.4 in Appendix 5). Details of the subgroup and follow-up period for each cost were also extracted. Where studies reported multiple costs (e.g. for different sub-groups, categories of care or follow-up periods), each cost was extracted separately. Where different studies reported costs for the same population but at different follow-up time points we extracted costs for the non-overlapping periods. Where reported, standard error was extracted or imputed using standard deviation and sample size or from confidence intervals.

All costs are presented in 2014 US international dollars. Costs were converted to 2014 prices [19], and then to US dollars adjusted for cost of living using the purchasing power parity (PPP) method [20].

\section{Statistical analysis}

Sample size and quality scores were pooled as unweighted means. Pooled estimates for gender, age, length of stay and operation performed were weighted using the sample size. Secular trend in study quality was assessed using an ordinary least squares model.

Pooled estimates of costs were calculated using the inverse variance $\left(1 / \mathrm{SE}^{2}\right)$ method [21]. Given the expected variation in follow-up time of data collection, we focused on costs occurring in two time periods: index hospitalisation and at 12 months following hip fracture. Hence, we only pooled studies reporting costs at these time points. The index hospitalisation refers to the initial inpatient admission immediately following hip fracture.

Where studies reported more than one cost, a two-level approach was used to pool costs allowing for grouping of costs within studies. At the cost level, the standard error for costs informed the weights. At the study level, weighting was calculated by estimating the pooled standard deviation before converting to a standard error. It was assumed that costs for subgroups were independent of each other. The use of a two level approach was contingent on the number of costs available. If too few costs were available (i.e. $n<10$ ), or the costs were from a single study, pooled estimates were calculated without using the multi-level approach. 
A two-level meta-regression was used to explore the association between initial hospitalisation costs and potential predictors of costs. The approach combines the pooling of cost data from different studies using a meta-analysis, accounting for within and between-study variation, using a generalised linear model with Gaussian family and identity link to estimate the costs given the sample characteristics. Covariates were judged to be statistically significant if $p<0.05$. We focused on index hospitalisation costs due to the expectation that they were the most commonly reported and consistent costs across all studies and represented a major contributor to costs during the first year following a hip fracture [3].

Where studies reported the total healthcare cost as well as costs for individual categories of care (e.g. inpatient care) at 12 months, the proportions of individual categories of care expressed in terms of total healthcare costs were estimated. The average of these proportions was used to estimate the proportion of total healthcare costs attributable to each category of care. Similarly, in studies reporting social care costs additionally to healthcare costs, the proportion of the social care costs as a percentage of total health and social care costs was estimated. All statistical analysis was performed using Stata 12 (Stata Corp, USA).

\section{Results}

Descriptive analysis

The literature search identified 113 studies that met the inclusion criteria and are included in the analysis (see Figure 1). Appendix 4 provides further information of included studies. 


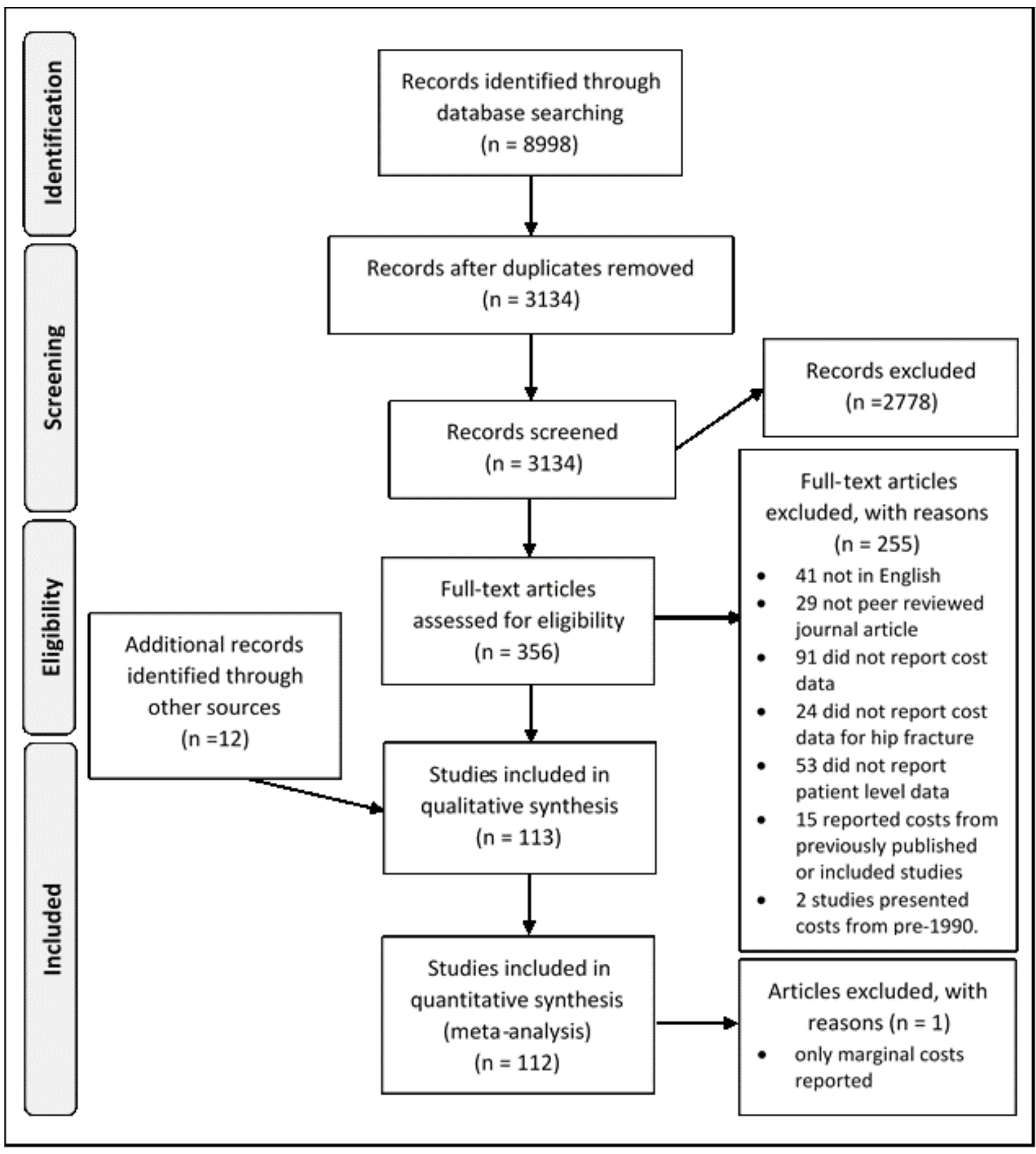

The 113 papers presented costs of hip fractures for 670,173 patients. The mean sample size was 5,930 (median 252, range 4 to 126,374). Table 1 presents details of the studies and details of enrolled patients. The average age at hip fracture was 80.2 years and the majority of patients were females (70.1\%). During index hospitalisation, the most common surgical procedures were internal fixation and hemi-arthroplasty (89\%). The mean length of stay for the index hospitalisation was 8.6 days (SE 1.1). However, mean length of stay varied significantly by region. Studies from North America reported the shortest mean length of stay, whilst studies from Asia had the longest length of stay. 
Table 1 - Baseline characteristics of enrolled participants.

\begin{tabular}{|c|c|c|c|}
\hline & & $\begin{array}{c}\text { Mean } \\
\text { (SE) }\end{array}$ & $\begin{array}{c}\text { Number of studies } \\
\text { reporting data }\end{array}$ \\
\hline \multicolumn{4}{|c|}{ Study details } \\
\hline Sample size ${ }^{a}$ & & $5,931(1,575)$ & 113 \\
\hline Study quality ${ }^{a}$ & & $71.1 \%(1.6)$ & 113 \\
\hline \multicolumn{4}{|c|}{ Demographic details } \\
\hline Age (years) ${ }^{b}$ & & $80.2(0.87)$ & 102 \\
\hline Gender (\% female) ${ }^{b}$ & & $70.1 \%(5.7)$ & 104 \\
\hline \multirow{8}{*}{$\begin{array}{l}\text { Length of stay, index } \\
\text { hospitalisation (days) }^{b}\end{array}$} & North America & $6.4(0.21)$ & 21 \\
\hline & Western Europe & $13.6(1.08)$ & 25 \\
\hline & Asia & $32.1(5.7)$ & 8 \\
\hline & Australasia & $19.8(2.8)$ & 3 \\
\hline & Latin America & $10.9(1.7)$ & 2 \\
\hline & Eastern Europe & No data & 0 \\
\hline & Middle East & $9.6(1.5)$ & 3 \\
\hline & Total & $8.6(1.1)$ & 62 \\
\hline \multirow{5}{*}{ Operation performed ${ }^{b}$} & Internal fixation & $46.6 \%(5.8)$ & \multirow{5}{*}{31} \\
\hline & Hemi-arthroplasty & $41.2 \%(4.7)$ & \\
\hline & $\begin{array}{l}\text { Total hip } \\
\text { replacement }\end{array}$ & $3.0 \%(1.2)$ & \\
\hline & Intramedullary nail & $1.2 \%(0.7)$ & \\
\hline & Other & $8.0 \%(0.05)$ & \\
\hline
\end{tabular}

a- unweighted

b - weighted by sample size

Year of publication and study quality

The year of publication of included studies ranged from 1993 to 2015 . The majority of studies $(n=63$, $56 \%$ ) were published after 2007 . Average study quality was $71 \%$. We found no significant association between study quality and year of publication $(p=0.359)$.

\section{Geography}

Costs were available from 27 different countries (see Table A5.3 in Appendix 5). The majority of studies assessed costs of hip fractures in North America or Western Europe ( $n=50,44 \%$ and $n=40$, $35 \%$ respectively). There were 11 studies from Asia, with Australasia, Latin America, Eastern Europe and the Middle East accounted for the remaining twelve studies. No studies were identified for the African region.

\section{Study design}

The majority of studies ( $n=103,91 \%)$ used an observational design with the remaining 10 studies (9\%) assessing costs as part of a randomised controlled study. Of observational studies, 71 (69\%) assessed the cost of hip fractures retrospectively, $28(27 \%)$ studies used a prospective design and four studies used a cross sectional design (4\%).

\section{Economic perspective and costing methodology}

The economic perspective of the included studies was explicitly stated in 33 papers and was derived from information provided within the study for the remaining studies. A payer perspective (e.g. HMO, Private insurer) was the most common $(n=36,32 \%)$, followed by a healthcare provider (e.g. 
hospital, primary care) perspective $(n=35,31 \%)$. A healthcare system perspective (e.g. National Health System) was adopted in 26 studies (23\%) and a societal perspective taken in the remaining 16 studies (14\%). Studies from North America were more likely to adopt a payer perspective and studies from Western Europe were more likely to take a system perspective $\left(\chi^{2}, p<0.001\right)$.

Resource use in the majority of studies was valued using national reference costs ( $n=51,45 \%)$ or costs from local finance departments ( $n=50,44 \%)$. Ten studies (9\%) used a combination of costs from national reference databases and local finance departments. The costing methodology was not stated or was unclear in two studies (2\%).

\section{Follow up period}

Nearly half of included studies (48 studies, 42\%) only reported costs related to the index hospitalisation. The most commonly reported length of follow up after the index hospitalisation was 12 months (38 studies, 34\%). Fourteen studies (12\%) reported a follow up period between the index hospitalisation and 12 months. The remaining 13 studies reported a follow-up period of more than 12 months. The majority of these (eight studies) reported a follow-up of 24 months (see Table A5.5 and A5.6 in Appendix 5).

\section{Subgroup analysis}

Subgroup analysis was performed by 44 studies (39\%). Eleven of these used multivariate analysis to explain the variation in costs by adjusting for several variables. Subgroup analysis was conducted on costs covering a range of different categories of care. Twenty-two studies conducted sub-group or regression analysis on index hospitalisation costs, seven on healthcare costs, 10 on direct costs and five on total costs. Of studies conducting sub-group analysis on healthcare, direct or total costs, six also reported sub-group analysis for the index hospitalisation resulting in a total of 28 studies reporting results of sub-group analysis for this category of care. Table 2 shows the number of studies assessing each variable and the direction of the association with costs.

Comorbidities prior to fracture were found to be associated with significantly higher costs in $80 \%$ of studies assessing this variable. Developing a complication after hip fracture was found to be associated with significantly higher costs in $93 \%$ of studies assessing this variable.

Female gender, internal fixation and enrolment in the intervention arm of a study (relative to control arm) were commonly associated with a significant decrease in costs relative to the reference group. Females were reported to be associated with statistically significant lower costs than males in six of the 14 studies in which gender was analysed. However, one study reported females to be associated with significantly higher costs than males.

There was limited or contradictory evidence of the association between costs and mean age of the sample, ethnicity, insurance status, residence prior to admission, functional status prior to admission, type of hip fracture and discharge destination.

Results of sub-group analysis for index hospitalisation costs reveal similar findings. 
Table 2 - Number of studies reporting results of sub-group or regression analysis. Breakdown of the number of studies finding statistically significant difference in results between groups (at the 95\% confidence level).

\begin{tabular}{|c|c|c|c|c|}
\hline \multirow[b]{2}{*}{ Subgroup } & \multirow[b]{2}{*}{ Number of studies } & \multicolumn{3}{|c|}{ Results of subgroup or regression analysis } \\
\hline & & Lower costs & $\begin{array}{c}\text { No } \\
\text { difference }\end{array}$ & Higher costs \\
\hline Older age & $12(11 \%)$ & 2 & 6 & 4 \\
\hline Female gender & $14(12 \%)$ & 6 & 7 & 1 \\
\hline $\begin{array}{l}\text { Black and minority ethnicity } \\
\text { (vs. white) }\end{array}$ & $2(2 \%)$ & 0 & 1 & 1 \\
\hline $\begin{array}{l}\text { Not resident in own home } \\
\text { prior to admission }\end{array}$ & $3(3 \%)$ & 1 & 1 & 1 \\
\hline Private insurance & $1(1 \%)$ & 0 & 0 & 1 \\
\hline $\begin{array}{l}\text { Impaired functional ability } \\
\text { prior to fracture }\end{array}$ & $2(2 \%)$ & 1 & 1 & 0 \\
\hline Comorbidity prior & $15(13 \%)$ & 0 & 3 & 12 \\
\hline $\begin{array}{l}\text { Inter-trochanteric fracture } \\
\text { vs. neck of femur }\end{array}$ & $4(4 \%)$ & 0 & 3 & 1 \\
\hline $\begin{array}{l}\text { Internal fixation vs. } \\
\text { hemiarthroplasty }{ }^{\text {a }}\end{array}$ & $10(9 \%)$ & 4 & 6 & 0 \\
\hline Intervention protocol & $7(6 \%)$ & 4 & 3 & 0 \\
\hline Developed complication & $14(12 \%)$ & 0 & 1 & 13 \\
\hline $\begin{array}{l}\text { Not discharged to own } \\
\text { home }\end{array}$ & $5(4 \%)$ & 0 & 2 & 3 \\
\hline
\end{tabular}

Reported results of sub-group analysis by variable assessed (index hospitalisation costs, $n=28$ )

\begin{tabular}{|c|c|c|c|c|}
\hline \multirow[b]{2}{*}{ Subgroup } & \multirow[b]{2}{*}{ Number of studies } & \multicolumn{3}{|c|}{ Results of subgroup or regression analysis } \\
\hline & & Lower costs & $\begin{array}{c}\text { No } \\
\text { difference }\end{array}$ & Higher costs \\
\hline Older age & $6(5 \%)$ & 1 & 4 & 1 \\
\hline Female gender & $9(8 \%)$ & 4 & 5 & 0 \\
\hline $\begin{array}{l}\text { Black and minority ethnicity } \\
\text { (vs. white) }\end{array}$ & $2(2 \%)$ & 0 & 1 & 1 \\
\hline $\begin{array}{l}\text { Not resident in own home } \\
\text { prior to admission }\end{array}$ & $1(1 \%)$ & 0 & 1 & 0 \\
\hline $\begin{array}{l}\text { Impaired functional ability } \\
\text { prior to fracture }\end{array}$ & $1(1 \%)$ & 0 & 1 & 0 \\
\hline Comorbidity prior & $10(9 \%)$ & 0 & 1 & 9 \\
\hline $\begin{array}{l}\text { Inter-trochanteric fracture } \\
\text { vs. neck of femur }\end{array}$ & $3(3 \%)$ & 0 & 2 & 1 \\
\hline $\begin{array}{l}\text { Internal fixation vs. } \\
\text { hemiarthroplasty }^{\text {a }}\end{array}$ & $7(6 \%)$ & 3 & 4 & 0 \\
\hline Intervention protocol & $5(4 \%)$ & 5 & 0 & 0 \\
\hline Developed complication & $10(9 \%)$ & 0 & 0 & 10 \\
\hline $\begin{array}{l}\text { Not discharged to own } \\
\text { home }\end{array}$ & $3(3 \%)$ & 0 & 2 & 1 \\
\hline
\end{tabular}

a -Except Gill et al which compared internal fixation to intramedullary nail. 
Hip fracture costs

In total, 607 costs were extracted from included studies, relating to all categories of care and a range of different follow-up periods. A standard error was available or imputed for 243 costs. Of these, 178 costs related to a single category of care (e.g. inpatient care) and 65 related to multiple categories of care (e.g. a combination of inpatient, outpatient and community care).

Index hospitalisation costs

Costs for the index hospitalisation were reported in 68 studies, providing 126 separate costs. This comprised 48 studies solely reporting index hospitalisation costs and 20 studies reporting costs for a longer follow-up but reporting separately the costs of index hospitalisation. Of these, 64 costs from 32 studies were reported with a standard error (Table A5.5, Appendix 5). The pooled mean cost for the index hospitalisation was $\$ 10,075(95 \% \mathrm{Cl} \$ 8,322-\$ 11,828)$.

Univariate analysis of index hospitalisation costs

Results of univariate multi-level regression analysis are available in Table A5.8 (Appendix 5). Certain geographic regions, studies reporting charges as opposed to costs, control groups of comparative studies, randomised controlled trials, post-fracture complications, older age, males, longer mean length of stay and older studies were associated with significantly higher costs.

\section{Multivariate analysis of index hospitalisation costs}

Results of the multivariate analysis are reported in Table A5.8 (Appendix 5). To avoid overfitting, studies from the US were compared with others. We found gender, year of study, US studies, and length of stay to be significantly associated with costs. Holding all else constant, studies published more recently were significantly associated with lower costs which may represent changes in clinical practice, fewer complications as well as methodological changes.

Furthermore, holding all else constant, in studies outside the US the mean cost per patient was $\$ 3,304$ less per additional day of length of stay compared to the US. On average, women were found to be statistically significantly less expensive than men, costing $\$ 134$ less per patient $(p<0.001)$.

The main source of variation between cost estimates was due to variation between studies as opposed to within studies (ICC $=0.939$ ).

\section{Costs after index hospitalisation}

Of the 607 costs extracted, 481 costs related to categories of care from a variety of follow-up periods not specific to the index hospitalisation (e.g. index rehabilitation, community healthcare costs, social care costs, productivity losses or aggregated costs combining several categories into a single figure). Of these, 179 costs were reported with standard errors, of which nine comprised index rehabilitation costs and the remaining 170 costs covered a range of follow-up periods from 45 days to 36 months (see Table A5.5 and A5.6 in Appendix 5).

The pooled estimate for index rehabilitation costs was $\$ 7,496$ (SE 4,688) based on four costs. The pooled estimate for the combined cost of the index hospitalisation and rehabilitation combined was $\$ 11,767$ (SE 571), based on five costs reporting a summary cost. 


\section{Hip fracture costs at 12 months}

After the index hospitalisation, the most commonly reported follow up period was 12 months (228 costs). Of these, 81 costs were reported with a standard error. Pooled costs for each category of care at 12 months following hip fracture are reported in Table 3.

Table 3 - Pooled mean costs for different categories of care at 12 months.

\begin{tabular}{|c|c|c|}
\hline Category of care & $\begin{array}{l}\text { Number of } \\
\text { Costs }\end{array}$ & Average cost (SE) \\
\hline Inpatient ${ }^{\text {a }}$ & 13 & $13,331(2,843)$ \\
\hline Inpatient (excluding index hospitalisation) ${ }^{b}$ & 3 & $1,311(1,178)$ \\
\hline $\begin{array}{l}\text { Rehabilitation (index and subsequent } \\
\text { rehabilitation) }^{\mathrm{b}}\end{array}$ & 3 & $12,020(3,330)$ \\
\hline Outpatient $^{\mathrm{a}}$ & 7 & $835(85)$ \\
\hline Primary care and community services ${ }^{b}$ & 4 & $543(223)$ \\
\hline Medical drugs ${ }^{a}$ & 7 & $140(31)$ \\
\hline Total healthcare costs ${ }^{a}$ & 11 & $13,820(4,005)$ \\
\hline Medical equipment and home modification ${ }^{b}$ & 2 & $1,859(2,387)$ \\
\hline Social care in the patient's home ${ }^{b}$ & 4 & $3,742(2,166)$ \\
\hline Social care in an Institutional setting ${ }^{b}$ & 3 & $2,839(2,303)$ \\
\hline Total social care costs ${ }^{b}$ & 2 & $6,851(6,960)$ \\
\hline Other direct cost ${ }^{\mathrm{b}}$ & 2 & - \\
\hline Health and social care costs ${ }^{a}$ & 11 & $43,669(12,241)$ \\
\hline Out of pocket expenses & 0 & - \\
\hline Income foregone by caregiver ${ }^{b}$ & 1 & $426(120)$ \\
\hline Income foregone by patient ${ }^{b}$ & 2 & $117(10)$ \\
\hline Productivity and informal care & 0 & - \\
\hline Total costs ${ }^{a}$ & 6 & $11,497(1,588)$ \\
\hline
\end{tabular}

a - two-level approach

b - single level approach

The estimate for total health and social care costs in the first year following hip fracture is $\$ 43,669$ per patient. Inpatient care is the single category of care with the highest cost, estimated at $\$ 13,331$. This is followed by the cost of rehabilitation care, estimated at $\$ 12,020$. However, the figure for rehabilitation costs is unexpectedly high due to the limited number of costs and a very high cost from one study. Excluding this study resulted in a mean cost of $\$ 6,269(2,094)$.

The index hospitalisation accounts for the majority of inpatient costs during the first 12 months. Eight studies reported both the costs of the index hospitalisation and total inpatient costs at 12 months (12 costs). On average, the index hospitalisation accounted for $79.6 \%$ of the total inpatient costs in the first year.

Seven studies reported total healthcare costs and total inpatient costs over the first year following hip fracture (nine costs). Inpatient costs represented $74.3 \%$ of the total healthcare costs in the first year following hip fracture. Six studies (seven costs) reported total health and social care costs and the costs of inpatient care in the first 12 months following hip fracture. Inpatient costs represented $62 \%$ of the total health and social care costs in the first 12 months.

Medication costs as well as total healthcare costs at 12 months were reported by four studies (six costs). Medication costs comprised, on average, $7.9 \%$ of total health care costs during the first year following hip fracture. Only two studies (four costs) reported both the costs of primary health care 
and total healthcare costs at 12 months. The cost of primary health care represented $7.7 \%$ of total healthcare costs.

Four studies (seven costs) reported the cost of social care as well as the total health and social care costs at 12 months. Social care accounted for on average $24.8 \%$ of health and social care costs during the first 12 months following hip fracture.

\section{Discussion}

Our study presents results of a systematic review of the costs of fragility hip fractures globally since 1990. We identified costs from 113 studies, including data on over 670,000 patients. Enrolled patients were predominantly older females from North America and Western Europe. We found the health and social care costs in the 12 months following hip fracture to be $\$ 43,669$. The index hospitalisation and total inpatient costs represent significant components of total cost in the first year following hip fracture. This is consistent with findings of other studies [22-24].

Variables identified as consistently associated with variation in hip fracture costs included patients with comorbidities prior to fracture and patients developing complications following hip fracture. There was some evidence that gender, fracture type and the operation performed may also be significantly associated with hip fracture costs. Evidence for the role of other factors such as age were less compelling with limited studies assessing the association or reporting conflicting results. There was little consistency in the variables included in subgroup and regression analysis across studies.

The average cost for the index hospitalisation following hip fracture was $\$ 10,075$ with significant heterogeneity between studies. Meta-regression analysis identified factors related to the country and healthcare system (e.g. region); the design of studies (e.g. interventional vs. control groups); and the patient sample (e.g. proportion that was female) to be statistically significant. We also found that, length of stay, gender, whether the study was conducted in the US and year of study were associated with the cost of care.

Analysis of index hospitalisation costs identified US studies as having a different profile compared with studies from other countries. The cost for additional bed days during the index hospitalisation in US studies was $\$ 3,304$ higher than non-US studies. This is due to studies in the US reporting shorter mean lengths of stay compared to other studies. Whilst mean costs of the index hospitalisation for US studies did not significantly differ from other studies $(p=0.157)$, due to differences in the length of stay, studies from the US had significantly higher costs per bed day.

Strengths and limitations

The systematic review identified a large number of studies from a range of countries. To our knowledge, this is the first study to undertake a systematic review of hip fracture costs, pooling costs for different categories of care and conducting a meta-regression analysis to investigate potential reasons for the heterogeneity observed.

The results reported in the present study can guide decisions on prevention measures and treatment strategies by providing insight into which patients incur the highest costs following hip fracture. Used in conjunction with data on benefit or utility from treatment and preventing falls, high risk groups can be identified that could benefit from targeted care. 
Limitations in the number of costs meant that only costs for the index hospitalisation could be robustly analysed using meta-regression techniques. Nearly half of studies only reported costs for the index hospitalisation, thus limiting the data available for analysis of longer follow up periods.

Whilst there were a large number of costs extracted, only $40 \%$ (243 costs) were reported with standard error. Consequently, with multiple different categories of care being assessed and different follow up periods, there were relatively few costs available to pool. Additional data would ensure more accurate pooled estimates of costs for different categories of care, with adjustments for differences between studies.

Additional data reporting index hospitalisation costs would also allow adjusting for a wider range of variables. For example, studies consistently reported patients with comorbidities or developing complications as incurring higher costs. However, it was not possible to include these two factors in our meta-regression as too few costs were available for analysis.

Many studies reported a summary cost (e.g. health and social care costs) without a breakdown of costs with standard deviations. Consequently, pooled estimates of 12 month costs for different categories of care are based on data from different studies. Hence, it was not possible to combine the various categories of care to obtain the total costs of hip fracture.

Results were weighted in the analysis using the inverse variance method in line with Cochrane Collaboration guidelines [25]. Using this method resulted in a number of studies carrying a relatively large weighting. Furthermore, as variance is related to the cost figure, studies with higher costs are expected to have larger variance and as such will be given a lower weighting. Alternative methods for weighting studies included using the size of the sample or the score for methodological quality. None of the weighting methods were ideal and the inverse variance method was used as this is standard practice in meta-regression.

Implications for Future Research

Meta-regression is a useful tool to adjust for differences between studies. We applied this technique to analyse costs of hip fractures. Whilst limitations exist in the use of meta-regression analysis for data on costs of care, the present study shows its potential usefulness.

Heterogeneity between studies is unavoidable. Guidelines and checklists for economic evaluations $[26,27,18,28,29]$ help ensure an appropriate standard of research and reporting of results of costing studies. However, we identified considerable variation in study designs, perspective and costing methodologies adopted, follow up periods and reporting of results that impaired comparisons and highlight the need for more standardisation.

The majority of studies identified in this review were observational and retrospective. In contrast, the most precise costs are to be obtained from prospective studies supported by a very detailed identification and valuation of resources. However, the optimal costing study faces a trade-off between the precision of the costs and the feasibility, time and costs associated with data collection. Furthermore, the optimal study design is a function of the research question being addressed. For example, costing studies alongside randomised trials could focus on estimating the expected key drivers of the cost differences between interventions with considerable detail and effort to the detriment of other costs. Comparative and cost-of-illness studies could equally be supported, in a relatively inexpensive way, by valid and precise costs from retrospective studies involving large medical databases that are comprehensive, up-to-date and of good quality. 
Study designs should be precise and cost-effective when estimating hip fracture costs. Therefore, it is important that such costing studies describe and justify the study design and provide sufficient details on how costs were derived including items such as: demographics of the sample; the types of costs included; a breakdown of cost by category of care; and a measure of variation or uncertainty around the reported estimates. As well as facilitating future evidence synthesis exercises, this information would improve the methodological quality of studies

Implications for Policy

Policy decisions regarding which interventions to invest or disinvest in require accurate data to inform cost-effectiveness analyses. We have shown that the available hip fracture costs can vary greatly depending on the methodology, care categories included and population sampled. For example, the costs for medical care in the 12 months following hip fracture in the US ranged from $\$ 21,259-\$ 44,200$ which can significantly influence the cost-effectiveness results supporting policy decisions.

This study identifies the need for policies to consider the context within which decisions are being made. Factors that may influence costs include the country from which costs are derived; how recent the costs estimates are; demographics of the sample; and the perspective of the study, including which costs were considered.

Additionally, whilst inpatient care represents a large component of overall cost, other health and social care represent a significant financial burden. Lost productivity from patients and carers may also present further financial burden, however, too few studies reported these costs to draw conclusions. Better policy decisions can be made if all medical costs as well as social care costs and productivity loss are considered. This 'societal' perspective is also considered best practice in economic research [30].

The results show that hip fractures place a high economic burden on health and social care systems. The costs incurred during the first year following hip fracture are greater than equivalent estimates for acute coronary syndrome $(\$ 32,345)$ and ischaemic stroke $(\$ 34,772)$ [31,32]. A meta-regression was used to combine heterogeneous studies presenting the cost of hip fracture to determine the factors driving costs of treatment. The impact of demographic factors such as gender, the methodology used to calculate costs as well as the country in which studies were conducted have been quantified. The results can be used to direct future research as well as identify sub-groups within the population that would be benefit from receiving preventative services. 


\section{References}

1. Cooper C (1997) Advances in the Epidemiology, Prevention, and Treatment of Osteoporosis and FracturesThe crippling consequences of fractures and their impact on quality of life. The American Journal of Medicine 103 (2):S12-S19. doi:http://dx.doi.org/10.1016/S0002-9343(97)90022-X 2. Johnell O, Kanis JA (2006) An estimate of the worldwide prevalence and disability associated with osteoporotic fractures. Osteoporosis International 17 (12):1726-1733. doi:10.1007/s00198-0060172-4

3. Leal J, Gray AM, Prieto-Alhambra D, Arden NK, Cooper C, Javaid MK, Judge A (2016) Impact of hip fracture on hospital care costs: a population-based study. Osteoporosis International 27 (2):549-558. doi:10.1007/s00198-015-3277-9

4. Woolf AD, Pfleger B (2003) Burden of major musculoskeletal conditions. Bull World Health Organ 81 (9):646-656

5. Dhanwal DK, Dennison EM, Harvey NC, Cooper C (2011) Epidemiology of hip fracture: Worldwide geographic variation. Indian Journal of Orthopaedics 45 (1):15-22. doi:10.4103/0019-5413.73656

6. Cole ZA, Dennison EM, Cooper C (2008) Osteoporosis epidemiology update. Current

Rheumatology Reports 10 (2):92-96. doi:10.1007/s11926-008-0017-6

7. Kanis JA, Oden A, Johnell O, Johansson H, De Laet C, Brown J, Burckhardt P, Cooper C, Christiansen C, Cummings S, Eisman JA, Fujiwara S, Glüer C, Goltzman D, Hans D, Krieg M-A, La Croix A, McCloskey E, Mellstrom D, Melton LJ, Pols H, Reeve J, Sanders K, Schott A-M, Silman A, Torgerson D, van Staa T, Watts NB, Yoshimura N (2007) The use of clinical risk factors enhances the performance of BMD in the prediction of hip and osteoporotic fractures in men and women. Osteoporosis International 18 (8):1033-1046. doi:10.1007/s00198-007-0343-y

8. Järvinen TLN, Sievänen H, Khan KM, Heinonen A, Kannus P (2008) Shifting the focus in fracture prevention from osteoporosis to falls. Bmj 336 (7636):124-126

9. Keen RW (2014) Pathophysiology of osteoporosis. In: Clunie GPR, Keen RW (eds) Osteoporosis. 2nd edn. Oxford University Press, Oxford, UK. doi:10.1093/med/9780198713340.003.0001 10. Borgström F, Johnell $O$, Kanis JA, Jönsson B, Rehnberg C (2006) At what hip fracture risk is it costeffective to treat? Osteoporosis International 17 (10):1459-1471. doi:10.1007/s00198-006-0107-0 11. Lim SS, Vos T, Flaxman AD, et al (2012) A comparative risk assessment of burden of disease and injury attributable to 67 risk factors and risk factor clusters in 21 regions, 1990-2010: a systematic analysis for the Global Burden of Disease Study 2010. The Lancet 380 (9859):2224-2260.

doi:http://dx.doi.org/10.1016/S0140-6736(12)61766-8

12. Chia PH, Gualano L, Seevanayagam S, Weinberg L (2013) Outcomes following fractured neck of femur in an Australian metropolitan teaching hospital. Bone and Joint Research 2 (8):162-168. doi:10.1302/2046-3758.28.2000177

13. Panula J, Pihlajamäki H, Mattila VM, Jaatinen P, Vahlberg T, Aarnio P, Kivelä S-L (2011) Mortality and cause of death in hip fracture patients aged 65 or older - a population-based study. BMC Musculoskeletal Disorders 12 (1):105. doi:10.1186/1471-2474-12-105

14. Moher D, Liberati A, Tetzlaff J, Altman DG (2009) Preferred reporting items for systematic reviews and meta-analyses: the PRISMA statement. Bmj 339. doi:10.1136/bmj.b2535

15. The World Bank (2015) GDP per capita (current US\$). The World Bank,, http://data.worldbank.org/indicator/NY.GDP.PCAP.CD

16. The World Bank (2015) Health expenditure per capita (current US\$). The World Bank,, http://data.worldbank.org/indicator/SH.XPD.PCAP

17. The World Bank (2015) Health expenditure, public (\% of total health expenditure). http://data.worldbank.org/indicator/SH.XPD.PUBL

18. Luengo-Fernandez R, Gray AM, Rothwell PM (2009) Costs of Stroke Using Patient-Level Data: A Critical Review of the Literature. Stroke 40 (2):e18-e23. doi:10.1161/strokeaha.108.529776 19. The World Bank (2015) GDP deflator (base year varies by country). The World Bank,, http://data.worldbank.org/indicator/NY.GDP.DEFL.ZS?end=2015\&start=1989 
20. The World Bank (2015) PPP conversion factor, GDP (LCU per international \$). The World Bank,, http://data.worldbank.org/indicator/PA.NUS.PPP

21. Deeks JJ, Higgins JPT, Altman DG (2011) Chapter 9: Analysing data and undertaking metaanalyses. In: Higgins JPT, Green S (eds) Cochrane Handbook for Systematic Reviews of Interventions Version 5.1.0. The Cochrane Collaboration, The Cochrane Collaboration,

22. French FH, Torgerson DJ, Porter RW (1995) Cost analysis of fracture of the neck of femur. Age Ageing 24 (3):185-189

23. Edwards C, Counsell A, Boulton C, Moran CG (2008) Early infection after hip fracture surgery: risk factors, costs and outcome. Journal of Bone and Joint Surgery, British 90 (6):770-777. doi:http://dx.doi.org/10.1302/0301-620X.90B6.20194

24. Lawrence TM, White CT, Wenn R, Moran CG (2005) The current hospital costs of treating hip fractures. Injury-International Journal of the Care of the Injured 36 (1):88-91.

doi:10.1016/j.injury.2004.06.015

25. Deeks JJ, Higgins JPT, Altman DG (2008) Analysing Data and Undertaking Meta-Analyses. In: Cochrane Handbook for Systematic Reviews of Interventions. John Wiley \& Sons, Ltd, pp 243-296. doi:10.1002/9780470712184.ch9

26. Baladi J-F, Menon D, Otten N (1998) Use of economic evaluation guidelines: 2 years' experience in Canada. Health economics 7 (3):221-227. doi:10.1002/(SICI)1099-1050(199805)7:3<221::AIDHEC341>3.0.CO;2-N

27. Husereau D, Drummond M, Petrou S, Carswell C, Moher D, Greenberg D, Augustovski F, Briggs AH, Mauskopf J, Loder E (2013) Consolidated Health Economic Evaluation Reporting Standards (CHEERS) statement. BMJ : British Medical Journal 346. doi:10.1136/bmj.f1049

28. Drummond MF, Jefferson TO (1996) Guidelines for authors and peer reviewers of economic submissions to the BMJ. Bmj 313 (7052):275-283. doi:10.1136/bmj.313.7052.275

29. Mogyorosy Z, Smith P (2005) The main methodological issues in costing health care services: a literature review.

30. Byford S, Raftery J (1998) Perspectives in economic evaluation. BMJ : British Medical Journal 316 (7143):1529-1530

31. Menzin J, Wygant G, Hauch O, Jackel J, Friedman M (2008) One-year costs of ischemic heart disease among patients with acute coronary syndromes: findings from a multi-employer claims database. Curr Med Res Opin 24 (2):461-468. doi:10.1185/030079908X261096

32. Mercaldi CJ, Siu K, Sander SD, Walker DR, Wu Y, Li Q, Wu N (2012) Long-Term Costs of Ischemic Stroke and Major Bleeding Events among Medicare Patients with Nonvalvular Atrial Fibrillation.

Cardiology Research and Practice 2012:13. doi:10.1155/2012/645469 